\title{
Technology innovation and diffusion in "less than ideal" climate policies: An assessment with the WITCH model
}

\author{
Enrica De Cian • Valentina Bosetti • Massimo Tavoni
}

Received: 19 May 2010 / Accepted: 17 August 2011 /Published online: 4 November 2011

(C) Springer Science+Business Media B.V. 2011

\begin{abstract}
This paper examines the dynamics of innovation in low-carbon energy technologies distinguishing between research and development and technology diffusion as a response to alternative climate policies. We assess the implications of second-best policies that depart from the assumption of immediate and global participation and of full technology availability. The analysis highlights the heterogeneous effects of climate policy on different energy R\&D programs and discusses the contribution of important determinants such as carbon price and policy stringency, policy credibility, policy and technological spillovers and absorptive capacity.
\end{abstract}

\section{Background and motivation}

The relationship between environmental policies and innovation has been extensively explored by numerous contributions from empirical, applied and theoretical literature. In the context of climate change, technological progress is paramount because energy, so far the major driver of harmful emissions, is a necessary input of production. Substitution plays a role to some extent but there are limits which are to be addressed with new methods of using energy and generating electric power. Innovation can increase the energy efficiency of existing technologies, expand the portfolio of abatement options available and introduce new products and processes in the end-use sector. To design climate policies that provide effective incentives to innovation, it is necessary to understand what drives technical change and what its implications are on the economic costs of policy.

Both issues have been addressed by the literature and also various reviews on the topic have appeared (Löschel 2002; Gillingham et al. 2008; Popp et al. 2009; Carraro et al. 2010). Two applied approaches to the issue of induced innovation ${ }^{1}$ have been highlighted.

\footnotetext{
${ }^{1}$ The notion of induced innovation was introduced by Hicks (1932) who established the link between the change in relative prices and technical change. In the context of climate policy, this term refers to the ability of climate policy to induce innovation.
}

Grateful acknowledgement is made for financial support provided by WWF and Allianz. The authors wish to thank the whole RECIPE project team.

E. De Cian $(\bowtie) \cdot$ V. Bosetti $\cdot$ M. Tavoni

Fondazione ENI Enrico Mattei and Euro-Mediterranean Centre for Climate Change, Venice, Italy

e-mail: enrica.decian@feem.it 
Econometric and empirical studies, by assessing the effects of existing policies, can provide information about the drivers of technological change on the basis of past experience. Modelling works, by relying on tools such as Integrated Assessment Models (IAMs), can simulate these relationships and help to evaluate future scenarios and potential outcomes.

To date, several Integrated Assessment Models with endogenous technical change have been proposed. The induced technical change hypothesis has been addressed using these models with two different focuses. The first analysed the implications on economy-wide innovation (Goulder and Schneider 1999; Sue Wing 2003; Otto et al. 2008; Carraro et al. 2009a, b; Hart 2008), whereas the second adopted a more narrow focus on the dynamics of innovation within the energy sector (Popp 2004; Bosetti et al. 2009a, b; Gerlagh 2008). Innovation is not monotonic in prices and differentiated effects can be expected on different forms of R\&D. In particular, Baker and Shittu (2006) showed how induced technical change might not be equally distributed to different energy R\&D programs. Differences emerge when comparing energy efficiency fossil fuel $R \& D$ versus carbon free $R \& D$ programs. Blanford (2009) came to similar conclusions.

This paper contributes to the second stream of literature by exploring how research and development (R\&D) and the diffusion of carbon-free technologies respond to alternative climate policies. Innovation can be incremental and improve energy efficiency but it can also be radical and lead to the development of new, breakthrough technologies. Within the framework of the RECIPE project (Luderer et al. 2011, this issue), a set of policy scenarios progressively departing from the assumptions of immediate and global participation and of full technology availability have been proposed. Whereas the implications on costs and technology portfolio have been addressed elsewhere (Luderer et al. 2011, this issue, and Tavoni et al. 2011, this issue), this paper unfolds the consequences on innovation, international knowledge diffusion and technological transfers in different policy scenarios. We explore the results obtained with the WITCH model because it is the only model of the three involved in the project which describes the different stages of technological change, from $R \& D$ to the diffusion and adoption phase. In addition, it accounts for international spillovers of knowledge and experience that can occur at each stage.

In this framework, we highlight how the design of policy architectures affects the various forms of energy innovation. Results indicate that a stringent policy target imposed on a small group of top innovator countries can lead to more innovation and technology diffusion than what could be obtained by enlarging the group to countries such as China and India. The reason is twofold. On the one hand, most innovative capacity is concentrated in Annex I countries. Second, adding one or two developing countries substantially increases the set of cheaper mitigation options available, reducing incentives to innovation and deployment of low carbon technologies. Policy credibility also plays an important role and determines the impact of delayed mitigation policies on innovation and diffusion.

Our analysis focuses on the composition of the mitigation portfolio and how such a portfolio varies under different climate policies with a focus on the energy sector. Whether a decarbonised economy is also more technologically advanced overall and whether a tradeoff exists between innovations carried out in different sectors of the economy are issues that have been addressed elsewhere (see Carraro et al. 2009b).

The remainder of the paper is organised as follows. Section 2 describes how endogenous technical change is accounted for in WITCH. Section 3 shows how a model-based approach can be used to identify the determinants of climate-related innovation. Section 4 illustrates how different drivers of innovation play out in a set of alternative climate policy regimes. Section 5 concludes. 


\section{WITCH: A model of endogenous knowledge innovation and technology diffusion}

To examine the effect of second-best policies on innovation, we use the WITCH model (Bosetti et al. 2006). WITCH is a regional integrated assessment model designed to assist in the study of the socio-economic dimensions of climate change. It is structured to provide information on the optimal responses of world economies to climate damages and to identify impacts of climate policy on global and regional economic systems.

The macro-economic structure of the model is fully integrated with a concise description of the energy sector which makes WITCH a hybrid model. Its top-down component consists of an intertemporal optimal growth model in which the energy input entering the aggregate production function has been expanded to characterise different usages and technologies. The model distinguishes between the power generation sector and the final use of primary sources. It includes six fuels (coal, oil, natural gas, uranium, traditional biomass and biofuels) and seven technologies for power generation (nuclear power, wind turbines and photovoltaic panels, hydroelectric power, traditional pulverised coal technologies and integrated gasification combined cycle with carbon capture and storage, denoted as IGCC + CCS and thermoelectric power plants fuelled with natural gas and oil). World countries are grouped in 12 regions that play a dynamic non-cooperative game and strategically interact on emissions, innovation and the use of fossil fuels. A climate module describes the effect of GHG emissions on concentrations, radiative forcing and temperature. The dynamic and game-theoretic structure of the model, the articulation of the energy sector and the endogenous treatment of technological progress make WITCH a suitable tool for the analysis of climate change which is an issue that requires balancing short to mediumterm investment choices with long-term, uncertain economic benefits and environmental responses.

The model characterises the technology advances that can occur in the energy sector of the economy, distinguishing between the invention/innovation phase and the process of diffusion. Innovation can lead to energy efficiency improvements as well as reduce the costs of breakthrough, carbon-free energy technologies which are still too expensive to be adopted on a large scale as a substitute for fossil-fuel-based options. In both cases, the process of innovation has similar dynamics. The creation of new knowledge is described by an innovation possibility frontier. Because new knowledge cannot be fully protected by patents and there is some unintended diffusion, international spillovers of knowledge through blueprints, the exchange of ideas between researchers and imitation are accounted for. This form of knowledge flow is also referred to as disembodied spillovers. Knowledge is produced not only standing on the shoulders of the giants (Kennedy 1964), which justifies the characterisation of intertemporal spillovers, but also on the shoulders of neighbours (Rosenberg 1982). In each given region, new ideas stem from the existing stock of energy knowledge in each country as well as the international pool of knowledge. Each country can benefit from foreign knowledge while only the recipient country has a sufficiently high absorptive capacity which in turn depends on the domestic knowledge stock. The distance from the technology frontier, defined as the gap of each region from the stock of knowledge in high-income countries (the international pool of knowledge) also plays a role. This formulation reflects the idea that there is not one single leader innovator but that the technology frontier consists of a knowledge capital built up from the contribution of different countries. High-income countries, which are the frontier, can still benefit from spillovers because of the heterogeneity of knowledge capital across countries. Different countries have various technology developments and therefore there is room for spillovers even among top innovator countries (Rosenberg 1994). Low-income countries 
can take advantage of the pool of available knowledge in industrialised countries because they are below the technology frontier (Gerschenkron 1962).

Breakthrough technologies account for those technologies that either do not exist or that have not yet reached the maturity stage of alternative, existing fuels. To achieve commercial success and become competitive, they necessitate dedicated R\&D investments. To mimic such a process, the cost of these options is described as a two-stage process. First, investments in $\mathrm{R} \& \mathrm{D}$ reduce costs to the point of making the technology economically competitive with the alternative fuel or technology currently used. Once available and commercialised, the deployment in an increasing number of countries leads to further cost reduction due to learning-by-doing effects. In other words, breakthrough technologies account for the possibility of substituting currently available technologies that can be constrained or phased out for social or environmental concerns. In the WITCH model, breakthrough technologies can substitute linearly nuclear power in the electric sector and oil in the final use sector. To give tangible examples, nuclear fission could be substituted with nuclear fusion, advanced nuclear technologies or large scale solar power, whereas oil could be replaced by second and third generation biofuels food (e.g. based on woody or grassy cellulose, microorganisms or algae) or through electrification of the transport sector. Learning-by-doing effects can bring down the cost of technologies that are already available such as wind turbines and solar photovoltaic panels. In the case of already deployed technologies, we assume that most cost reduction comes from their diffusion and increased use. Appendix I provides a detailed and rigorous description of the modelling features discussed in the present section.

\section{Determinants of climate-related innovation}

Change in relative prices is one of the first drivers of technical change that has been stressed by the literature (Hicks 1932; Binswanger and Ruttan 1978). When one input becomes more costly, firms tend to economise on its use either by substituting with other factors or by adopting completely new products and processes of production. Therefore, relative price changes can induce substitution as well as technical change. The change observed in patent data following the oil shock price of the 1970s is an emblematic example confirming this effect. Popp (2002) used energy price data from 1970 to 1994 in the U.S. and found evidence for price-induced innovation although diminishing returns exist and the effect drops quickly over time.

In the context of climate policy, this implies that the relative price change, induced by a carbon tax can have important effects in scaling-up and redirecting innovation. Therefore, a first driver of climate-related innovation is the price of carbon, or in a cap-and-trade system, the stringency of the total cap on emissions. The carbon price reflects marginal abatement costs which tend to increase disproportionally with the severity of the abatement target, reflecting the non-linearity of marginal abatement costs in atmospheric GHG concentration targets.

Bosetti et al. (2009a, b) explored how the inducement effect varies with the stringency of climate policy and confirmed the vision that a more severe policy, leading to a higher carbon price, stimulates more energy innovation. However, Bosetti et al. also find that the price impact is differentiated by the type of $R \& D$ program and by technology. Incremental $\mathrm{R} \& \mathrm{D}$ that allows for a more efficient use of energy in existing technologies responds differently compared to innovation aimed at introducing new technologies and also compared to the diffusion of already existing alternatives such as renewables. A loose target 
(650 ppm $\mathrm{CO}_{2}$-eq) can almost double the deployment of renewables. The effect on energy efficiency innovation is instead more limited because some energy efficiency improvement already occurs without any climate policy due to other reasons such as the economic costs of energy. However, when the target is lowered to $550 \mathrm{ppm} \mathrm{CO}_{2}$-eq, the carbon price increases by about 10 times in 2050, driving a four-fold increase in R\&D investments and a further reduction of the costs of already deployed technologies. A sufficiently high carbon price is also needed to attract investments for the development of breakthrough technologies. R\&D investments in breakthrough technologies take some time before having a concrete impact on technology deployment. Because of decreasing marginal returns, the productivity of these investments is initially very high when deployment or installed capacity is low and then declines gradually as the knowledge stock builds up. Once the technology becomes competitive, then learning-by-doing further reduces its costs, while the importance of research and development investments diminishes. To summarise, diffusion of existing carbon-free technologies already occurs at low prices, whereas to stimulate both incremental and breakthrough energy innovation, the price incentive has to be sufficiently high.

A second driver of innovation is the credibility of the carbon price. Although the issue of policy stability and credibility has been a key issue in other fields such as regulatory risk, investment decisions and foreign direct investments, it has received less attention in the climate policy discussion. The more recent climate change debate has shifted from the issue of how much we should cut emissions to the issue of how to deliver such reduction. Large investments are required but more importantly the mix of investments has to be appropriately designed (Bastianin et al. 2010). For this reason, relative prices and credible policies play a crucial role. For example, Nemet (2010), using a panel of data from the wind industry, showed that policy was a strong determinant of the development and deployment of wind turbines and that in general policy, volatility can have strong impacts on investments in technologies with a high learning potential. Bürer and Wüsternhagen (2009) survey 60 investment professionals from European and American venture capitalist and private equity funds to confirm that private investments are attracted by stable policies.

R\&D investments can be very sensitive to this variable, especially those in risky programs aimed at developing technology options that are not available and therefore have a more uncertain performance (Baker and Shittu 2006; Blanford 2009). Bosetti and Victor (2010) examined the role of climate policy credibility in the context of an optimal growth integrated assessment model where the default assumption is that agents are forwardlooking and therefore short-term actions reflect what would happen throughout the optimisation scenario. In the paper, they analyse the implications of shortening the time horizon over which investors can envision 15,10 or 5 years. As expected, they show that the effect of credibility is stronger on breakthrough innovation than on incremental innovation aimed at improving energy efficiency of exiting technologies.

Because countries interact with each other through many channels such as energy markets, international trade, capital flows and the exchange of researchers and ideas, innovation is likely to respond to climate policies enacted in other countries as well which is a third determinant of innovation. On the one hand, domestic innovation can directly respond to regulations abroad (Popp 2006; Popp et al. 2007). On the other hand, domestic innovation can respond to increased innovation in foreign countries, perhaps induced by climate policy, supporting the view that knowledge spills across countries. Coe and Helpman (1995) is the most quoted study empirically supporting the existence of international knowledge spillovers, though not in the context of climate change. They 
showed that both domestic and foreign R\&D explain advances in total factor productivity. Peri (2005) studied the flow of knowledge across different countries in Europe and in North America, finding that aggregate innovation depends on internal and external knowledge. More recently, Verdolini and Galeotti (2009) used patent data for a group of OECD countries to study the determinants of innovation and the channels through which knowledge flows across countries. They suggested that more knowledge flows occur between innovator leaders and between similar countries.

The role of international knowledge spillovers is crucial in the context of climate change because $R \& D$ is concentrated in a few industrialised countries. A recent paper by Dechezleprêtre et al. (2009), using patent data for 13 classes of technologies, confirmed that innovation in climate-related technologies is concentrated in Japan, Germany and the U.S. which account for two thirds of global innovation.

The two factors, policy credibility and international policy, interplay in interesting ways. If international spillovers are taken into account, the ability to foresee a policy target will also affect the degree of knowledge diffusion. Bosetti et al. $(2009 \mathrm{a}, \mathrm{b})$ used the WITCH model to study innovation and diffusion when OECD countries undertake earlier abatement and other countries join later. Climate policy induces innovation in OECD countries. As a reaction, non-participatory countries, as for example China, could behave myopically and do not anticipate future climate targets. In this case, they would not be able to fully benefit from the policy-induced innovation in OECD countries because they would not have the incentive to build up sufficient absorptive capacity by investing in energy R\&D themselves. They could benefit from technology diffusion, only in a second moment, once the technology reaches commercialisation. Conversely, if policy credibility allows firms and policy-makers in these countries to anticipate the target, innovation will take place even before the target becomes binding and non-OECD countries will participate in the innovation activity. This adds to the global knowledge stock and simultaneously enhances their ability to absorb foreign knowledge. Indeed, absorptive capacity is another (the fourth in our list) determinant of innovation.

Knowledge spillovers and technology transfers are neither automatic nor costless but they require adoption capabilities such as human capital and indigenous research capacity. Moreover, not all types of transfer require the same effort. Material transfers (e.g. seeds and machineries) do not require particular abilities. Design transfers (e.g. blueprints, formulas and handbooks) need more engineering capacity. Capacity transfers and disembodied spillovers (e.g. scientific knowledge, technical capacity or capability) can be exploited only in the presence of skills and competencies to evaluate and use technical information (Grossman and Helpman 1991).

The stock of knowledge, which has been identified as a supply-side determinant of technological change (Schmookler 1966), is one possible indicator of absorptive capacity. However, the overall level of knowledge can have two opposite effects. On the one hand, it can reduce the scope for international spillovers because there is less that can spill over. On the other hand, it can increase the scope for spillovers because it augments the absorptive capacity. A set of recent empirical studies, assessing the technology transfers embedded in Clean Development Mechanism (CDM) projects, indicates that the second effect tends to be stronger, confirming the importance of capability in receiving countries (Dechezleprêtre et al. 2008; Seres et al. 2009). Verdolini and Galeotti (2009) also confirmed that knowledge increases the ability to benefit from disembodied international spillovers in the context of energy-efficient innovation. Keller (2004) reinforces this view in his survey of international knowledge spillovers by showing that an R\&D effort is needed to absorb international knowledge. 
The WITCH model considers the role of both international spillovers and absorptive capacity. The latter is measured as the ratio of a country's knowledge capital stock to the technological frontier. Countries that are further away from the technological frontier are less capable to absorb knowledge from the international knowledge pool because they lack laboratories, scientific bodies and researchers that make it possible to exploit foreign knowledge. As shown in Table 1, industrialised countries have larger knowledge stocks.

On the one hand, this leads to a larger absorptive capacity. On the other hand, it reduces the distance from the technological frontier. Which effect prevails is an empirical question. The empirical literature reviewed above indicates a larger role for absorptive capacity but a different answer might emerge when different determinants of innovation are simultaneously considered. Having identified four determinants of climate innovation, the next section examines the interplay between these forces in a selection of policy scenarios analysed within the RECIPE project.

\section{The implications of "less than ideal" climate policies on innovation and technology diffusion}

In order to investigate the determinants of climate-induced innovation, this paper focuses on a subset of the scenarios examined within the RECIPE project. We first present the case of immediate and global action aimed at stabilising $\mathrm{CO}_{2}$ concentrations at $450 \mathrm{ppm}$. In this setting, we examine the implications of three different permit allocation schemes: contraction and convergence, common but differentiated convergence and GDP shares. On the one hand, the status of international negotiations on climate change suggests that an international climate policy regime will not emerge easily. On the other hand, numerous regional initiatives are being implemented. To explore the consequences of fragmented regimes, we look at the case of delayed global action to $2020^{2}$ with early action by a progressively increasing number of countries. First, the EU acts as a first-mover being the only region with a unilateral climate policy between 2010 and 2020 when all regions are assumed to agree on an international scheme. The second case expands the group of firstmover countries to all Annex I countries and finally, in the third case, Annex I countries together with China and India face a climate policy already from 2010.

Section 3 identified the credibility of policy as an important driver of innovation. For this reason, we examine the role of expectation by considering the variants of the delayed global action to the 2020 case, with and without anticipation of the future policy target before 2020 .

The RECIPE project highlighted the fundamental role of technology to prevent dangerous climate change in a cost-efficient way. However, various reasons (e.g. R\&D failure, social acceptability etc.) could set obstacles to the diffusion and the large-scale deployment of each given option. As a matter of fact, there are drawbacks for each technology. Consider for example the competition with land for renewables and first generation biofuels, the risk of $\mathrm{CO}_{2}$ leakage for the technologies that plan to deploy $\mathrm{CCS}$, the risk of accident, waste disposal and proliferation risk for nuclear. The value of each given technology option is carefully analysed in Tavoni et al., this issue. Here, we examine the implications of two technologies that play an important role in reducing emissions in the power sector: nuclear power and the coal in IGCC plants equipped with carbon capture and storage (IGCC+CCS).

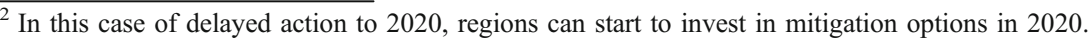




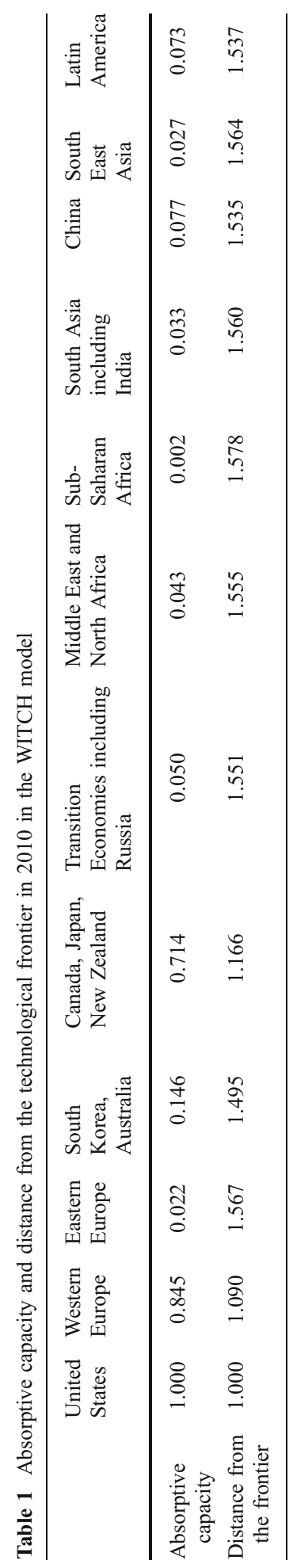




\subsection{Burden sharing}

The previous section discussed how both the regional composition of knowledge and carbon prices influence the way climate policy induces innovation. Varying the regional allocations of abatement effort can have an effect on the level of innovation and technology diffusion, although this effect is modest as long as international trade of emission permits guarantees an efficient allocation of the abatement effort. To better illustrate this effect, we compare the innovation effort in energy efficiency and in a breakthrough technology that could occur in the final use sector under three different permit allocation rules:

- Contraction and Convergence (C\&C): The C\&C scheme (Meyer 2004) envisions a smooth transition of emission shares from status quo (emissions in 2005) to equal per capita emissions in 2050. It combines elements of grandfathering - allocation based on historic emissions - and equal per capita emissions;

- Common but differentiated convergence (CDC): The CDC scheme is similar to the contraction and convergence scheme but, to account for historic responsibility, it entails more stringent reductions for industrialised countries, resulting in per-capita allocations below world average after two decades. Countries that do not belong to Annex I of the UNFCCC are allocated according to their business-as-usual trajectory until their emission allocation is more than $20 \%$ above global average per capita emissions. After crossing this 'graduation threshold', per capita allocations converge within 40 years to the level of the industrialised countries;

- GDP shares: Emission allowances are allocated in proportion to GDP shares, i.e. equal right of emission per unit of GDP.

These three allocation schemes require a decreasing effort by OECD countries, with the $\mathrm{C} \& \mathrm{C}$ being the case that allocates less emission permits to industrialised countries and GDP share the scheme under which they receive more allocation. Figure 1, left panel, shows the emissions allocated to industrialised countries under the three schemes described above. Moving from a CDC or C\&C allocation to a burden-sharing rule based on GDP shares almost doubles the initial allocation to OECD countries. In Fig. 1, the right panel plots the percentage change in $R \& D$ investments against the absolute allocation difference between the GDP share and the CDC case. Reading the graph from right to left, in the GDP share case, the lowest R\&D investments occur when industrialised countries are allocated about
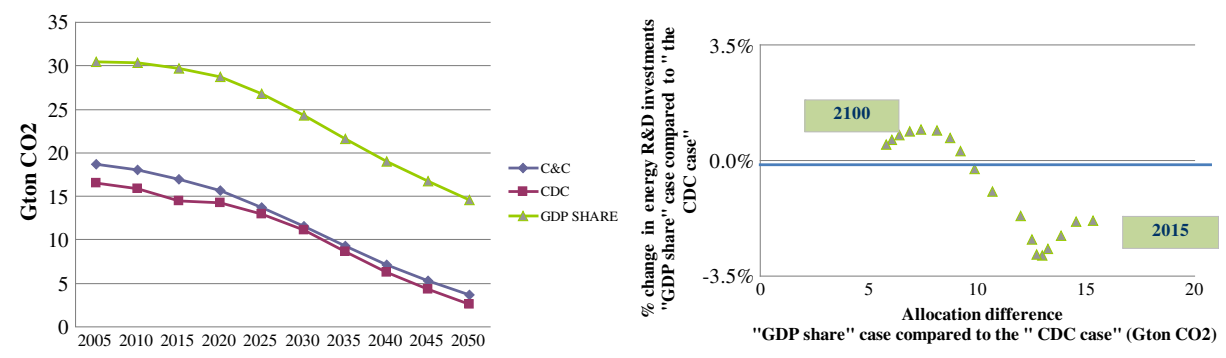

Fig. 1 Emission allocation to industrialised countries (left) and total energy R\&D investments (right). The right panel plots total energy R\&D investments in the "GDP share case" as a percentage change compared to the "CDC case" against the absolute allocation difference on the $\mathrm{x}$ axes. Under the GDP share allocation scheme, in 2010 developed countries received $15 \mathrm{GtonCO}_{2}$ more than in the $\mathrm{CDC}$ case 
$15 \mathrm{GtonCO}_{2}$ more than in the $\mathrm{CDC}$ case. Moving to the left, as the two allocation schemes converge, R\&D investments in the two cases become closer and the percentage change becomes close to zero. There is an inverse relationship between overall investments in innovation and the amount of permits allocated to richer countries, which increases from the left to the right.

In the GDP share case, during the first half of the century, overall R\&D investments are about 70 US\$ billion less compared to the CDC case. This corresponds to an average annual decrease of 1.4 US\$ billion. This reduction takes place mostly in OECD countries, with negative repercussion in non-OECD regions as well. In the long-run, this tendency is reverted in OECD countries, whereas innovation investments in non-OECD remain below $\mathrm{CDC}$ and $\mathrm{C} \& \mathrm{C}$ levels.

The higher level of innovation when industrialised countries are allocated fewer emission permits is due to the macro-economic distributive effects of different allocation schemes and the international spillovers of knowledge. When confronted with a tougher mitigation target, OECD countries respond by buying more permits but also by increasing the innovation effort as they are the repositories of the largest knowledge stocks. Given the international spillovers of knowledge, the increase in innovation investments is not necessarily accompanied by higher costs (see for example Bosetti et al. 2010). It should be noted that overall, the reduction in the R\&D effort is relatively small, of about $2-3 \%$ compared to the $\mathrm{CDC}$ case. It is thus important to stress that, although stricter allocations to developed countries imply more innovation globally, these effects are modest. Independently of the initial permit allocation, whenever climate stabilisation is to be achieved, the R\&D effort must significantly increase compared to the BAU. To give a sense of magnitude, R\&D investments in 2010 increases from 9 to between 48 and 50 US\$ billion in all of the stabilisation scenarios considered here.

\subsection{Progressive action}

When OECD countries are asked to reduce emissions relatively more or before other countries and no international carbon market is in place, ${ }^{3}$ there are at least three reasons to expect higher innovation globally. First, the knowledge stock in OECD countries is larger and, as mentioned in the previous section, this is one of the drivers of innovation. Second, the energy intensity of output and the carbon intensity of energy in OECD countries are already below world averages, hence they need to innovate more to reduce emissions, improving energy efficiency performance further and deploying alternative, more innovative technologies.

On the contrary, non-OECD countries can achieve significant emission reduction with cheaper options such as substituting coal with less polluting fuels like oil and gas. In addition, given their rapid economic growth, the rate of capital turnover is higher and therefore replacement with new and more efficient machinery and equipments is easier. The third factor, which relates to different regional distribution of abatement opportunities, is that when OECD countries move first, they lack an important mitigation option, which is the purchase of carbon offsets in the international market. De Cian and Tavoni (2010)

\footnotetext{
${ }^{3}$ International trade of emissions credits is already possible through the CDM of the Kyoto Protocol, but the numerous inefficiencies of the current procedures make it hard to consider CDM as a good proxy for an efficient, global carbon market.
} 
confirmed that delaying the availability of an international carbon market induces more innovation and more technology deployment in OECD region. Furthermore, they find that this is also true elsewhere. Because there are international spillovers, the benefits of innovation are transmitted to other countries as well. When climate policy is progressive and a group of countries acts as a first mover, two effects can be studied. First, what is the effect of broadening immediate participation to a larger number of countries? Second, what is the effect of tightening the target of early movers? Below, we explore both cases.

As a benchmark of comparison, let us consider the situation in which cooperation on climate change is delayed to 2020 and all countries follow BAU behaviours until that date. We compare what will happen to innovation and technology diffusion if an increasing number of countries undertakes earlier action. Figure 2 shows how regional investments in two different innovation programs aimed at either improving energy efficiency or reducing breakthrough technology costs in the final sector.

If the EU alone moves first, investments in energy efficiency R\&D throughout the century will be lower than in the case of delayed action. Until 2020, R\&D investments are lower because, by assumption, regions follow a BAU path and start investing in migration option only in 2020. As soon as agents can optimise to achieve the stabilisation target, from 2020 onward, they catch up and do more R\&D than what they would have done if the EU had gone first. This holds for EU, the OECD countries group (blue bar in Fig. 2), and nonOECD regions (pink bar in Fig. 2) as well. Because the benefits of energy efficiency R\&D occur right after investments are made (in the model one period time lag, corresponding to 5 years), it represents an important lever in delayed scenarios.

Expanding the set of first mover countries from Europe to other Annex I countries reduces investments in energy efficiency R\&D even more, and adding China and India emphasises this tendency further. Europe is the most energy and carbon efficient country and therefore, when less efficient countries are included into the international carbon market, the set of low-cost abatement options expands. Countries can decide to abate less domestically and buy more permits if this is cheaper than innovating or deploying advanced technologies at home. Significant emission reduction can be achieved by curbing down fossil fuel demand. For example, let us consider the case of coal.
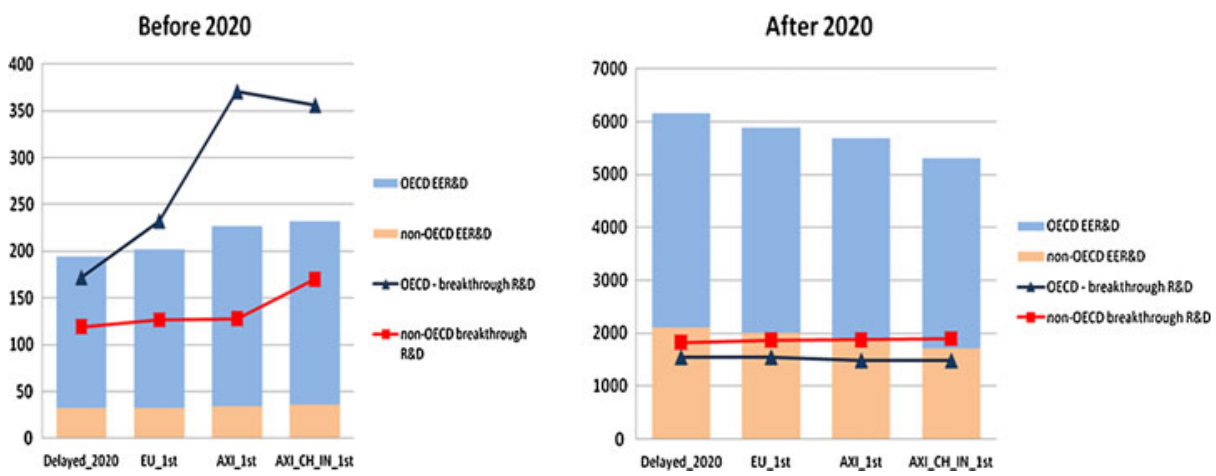

Fig. 2 Cumulative investments for energy efficiency improvement R\&D (EER\&D) and breakthrough R\&D (breakthrough R\&D) before and after 2020 (2005US\$ billion) when all countries start reducing emissions from 2020 onward (Delayed_2020); the EU moves first and implements climate policy before 2020 (EU_1st); Annex I moves first and implements climate policy before 2020 (AXI_1st); Annex I, China and India move first and implement climate policy before 2020 (AXI_CH_IN_1st). In the case of delayed 2020 case, investments start in 2020 
When the EU alone moves first, the stabilisation policy reduces the use of coal in power generation by $5 \%$ at maximum throughout the century, compared to the case of delayed action until 2020. Adding Annex I countries to the first movers group reduces the coal demand between $7 \%$ and $25 \%$. By extending early participation to China and India, the reduction boosts further up to $30 \%$.

An opposite tendency is observed when looking at innovation dedicated to breakthrough technologies (red and blue lines in Fig. 2). Let us first concentrate on what happens to R\&D investments in OECD countries (blue line in Fig. 2). Increasing the number of first movers has a positive effect on this form of innovation, especially in OECD countries, as long as the new members are R\&D-intensive countries (that is moving from EU_1st to AXI_1st). The marginal effect of further extending participation to China and India is negligible and slightly negative. This latter case is the only one for which results differ when looking at non-OECD R\&D investments (red line in Fig. 2). Indeed, non-OECD countries benefit more from innovation and deployment when China and India move earlier.

When the coalition of first movers includes top-innovator countries, tightening the target for early participants can lead to more innovation than enlarging the coalition to other nonAnnex I countries such as China and India. The reason is twofold. First, most innovative capacity is concentrated in Annex I countries. Second, adding developing countries expands the set of cheaper mitigation options available, reducing the incentive for costly mitigation activities such as innovation and deployment of low-carbon technologies. Let us consider the situation in which Annex I countries move first and they reduce their emissions more to meet a $30 \%$ reduction in 2020 compared to 1990 . Figure 3 shows the net effect of these forces on energy efficiency innovation and deployment of renewables (wind and solar, W\&S). Results are expressed as percentage changes compared to the case of broader participation by Annex I plus China and India, denoted as AXI_Ch_In_lst in the graph.

The comparison of how the deployment of renewables and investments in energy efficiency $R \& D$ change in response to a stringent target clarifies the differences that lie between technology diffusion on the one hand and the international transmissions of knowledge on the other hand. The international diffusion of marketed technologies, such as renewables, occurs with the reduction in investment costs, which is mainly driven by the global deployment (or experience, embodied spillovers). On the contrary, the diffusion of energy efficiency knowledge occurs because of the presence of disembodied spillovers. The size of benefits from knowledge spillovers largely depends on the absorptive capacity which in the model is approximated with the domestic stock of knowledge. The lack of such capacity can represent a barrier that reduces the scope for spillovers. As shown in

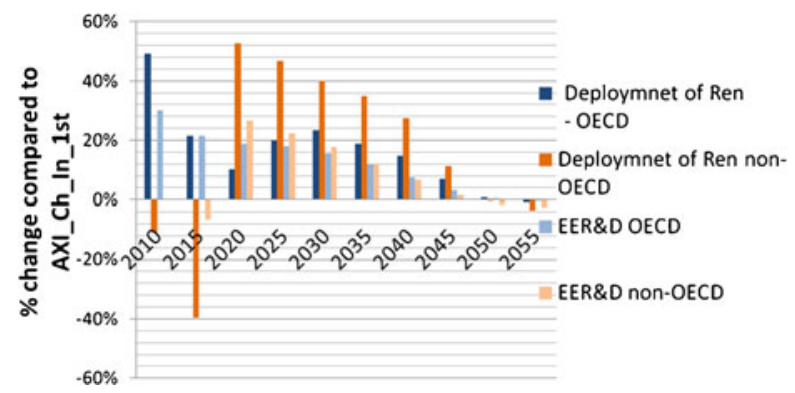

Fig. 3 Energy efficiency R\&D (EER\&D) and deployment of renewables when Annex I face a more stringent target before 2020 (30\% emission reduction) and non-Annex I join in 2020. Comparison with respect to the case where China and India participate with Annex I from the beginning and others join in 2020 
Fig. 3, a more stringent target for the OECD countries boosts their innovation investments compared to the case of broader participation and this induces a positive effect also in nonOECD, though with a time lag of about 10 years.

Both R\&D investments and the use of renewables increase. However, the increase in deployment is larger than that in innovation, both in percentage and in absolute terms. The increase in renewables is more pronounced as there are less obstacles to experience and technology diffusion, while low absorption capacity negatively affects the potential gains from knowledge spillovers.

Finally, it should be pointed out that the variations induced by different permit allocation rules or alternative architectures are limited by the fact that stabilising $\mathrm{CO}_{2}$ concentration at $450 \mathrm{ppm}$ already requires a major switch in investments and innovation.

\subsection{Myopic versus foresighted progressive action}

In this section, we explore the role of credibility and expectations about future policies. The lack of policy credibility leads to myopic behaviours and the postponement of any anticipatory action. When the moment of climate policy comes, countries are unprepared and have to incur in very high innovation expenditure. Figure 4 illustrates this concept by comparing the profile of different forms of innovation when the future climate target to be enforced from 2020 onward is anticipated or not.

The case with immediate action provides the benchmark because the intertemporal and sectoral profile of innovation is chosen so as to guarantee cost-effectiveness. By comparing the benchmark with immediate action with two future climate targets that differ only in the fact that one is anticipated while the other does not shed light on the efficiency loss and the additional costs of postponing action.

When the target is not anticipated, countries initially underinvest in all forms of innovation and in particular in more risky $\mathrm{R} \& \mathrm{D}$ programs associated with advanced breakthrough technologies (left-panel, "myopic" scenario). When the policy arrives in 2020 as a shock (right-panel, "myopic" scenario), countries need to spend more on innovation and priority is given to energy efficiency $R \& D$ which is immediately effective.

If the policy is anticipated, the additional expenditure on overall energy innovation will considerably be higher than in the myopic case and thus the efficiency loss will be lower. The efficiency loss in the time allocation of innovation and diffusion also leads to a
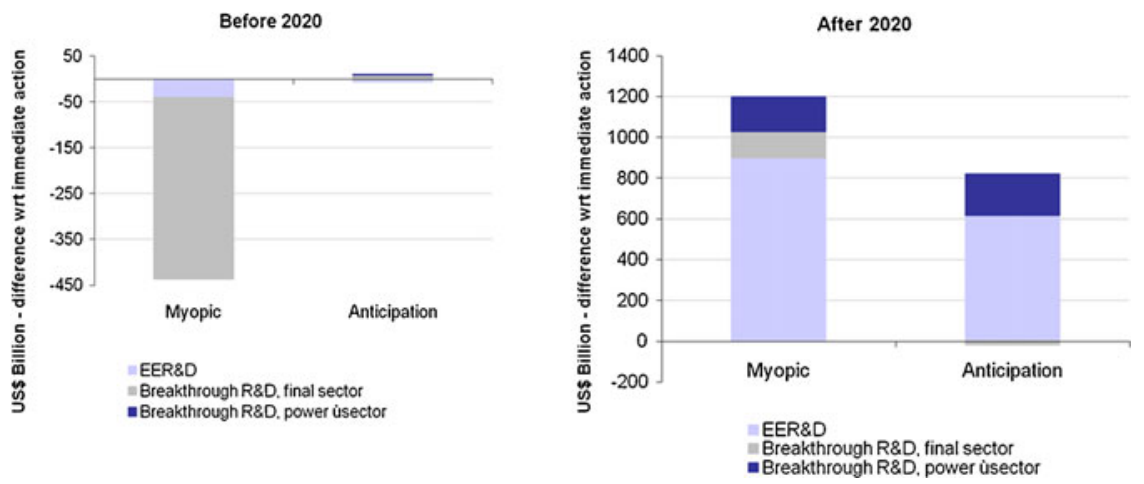

Fig. 4 Innovation in energy efficiency (EER\&D) and breakthrough technologies (breakthrough R\&D) before and after 2020 (2005US\$ billion) 
Fig. 5 Energy $\mathrm{CO}_{2}$ global emissions when all countries immediately cooperate (immediate) when action is delayed to 2020 but countries anticipate the future commitment (2020-anticipation) and when action is delayed to 2020 and countries do not anticipate the future commitment (2020-myopic)

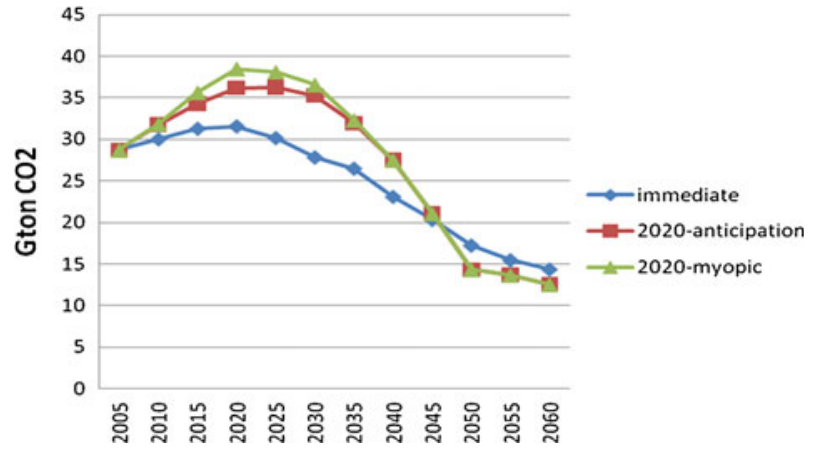

macroeconomic penalty of 0.7 percentage point difference in the "myopic" scenario and of 0.4 in the case with anticipation ("anticipation" scenario). The economic penalty is measured as additional consumption loss compared to the benchmark case with immediate action using a $3 \%$ discount rate. The benchmark case entails a discounted consumption loss of $1.37 \%$. Delayed action increases the loss to $1.73 \%$ in the "anticipation" scenario and to $2.07 \%$ in the "myopic" scenario.

Even when countries can foresee the policy, they do not have any target until 2020 and therefore the time window to act is narrower. Although anticipation leads to some early emission reduction, still the emission profile follows the myopic path quite closely (Fig. 5).

As a consequence, they still invest more than in the benchmark (right-panel, "anticipation" scenario) because when the policy is enacted, they will have lost some of the mitigation opportunities such as, for example, fuel switching.

The ability to anticipate that in the future there will be a climate target modifies the composition of the energy innovation portfolio. Early investments go to those innovation programs that take more time to contribute to emission reduction such as breakthrough $\mathrm{R} \& \mathrm{D}$ programs. If agents have a long-term planning perspective, they will anticipate the need to reduce emissions in final use sectors, knowing that their decarbonisation is more difficult and requires innovative technologies which are not yet available. A similar tendency is also observed in the power sector. On the contrary, energy efficiency innovation can be postponed because its contribution to emission reduction is more immediate.

It is worth emphasising that when mitigation is postponed, the intertemporal path of innovation is less efficient compared to the benchmark situation in which a wider time window is available. Because countries must meet the same climate objective, but within a shorter time frame, they invest more and less efficiently in later periods.

\subsection{Technology failure}

This section does not consider alternative architectures of climate policy but explores how the unavailability of some technologies affects R\&D investments and technology deployment. Nuclear power and the use of coal in IGCC plants equipped with carbon capture and storage (IGCC+CCS) are two attractive mitigation options. ${ }^{4}$ Nuclear is already widely used in a number of countries, whereas coal with CCS is very promising but so far it is has not been used for large-scale power generation. There are reasons to believe that both

\footnotetext{
${ }^{4}$ In the WITCH model, CCS can only be applied to power sector technologies and not to other sectors such as industry.
} 
Fig. 6 Additional investments in energy efficiency R\&D (EER\&D) and breakthrough technologies (Breakthrough R\&D) when either nuclear power (light blue bars) or coal IGCC with CCS (dark blue bars) is not available. Difference (2005 US\$ billion) compared to the case of immediate action with all options available

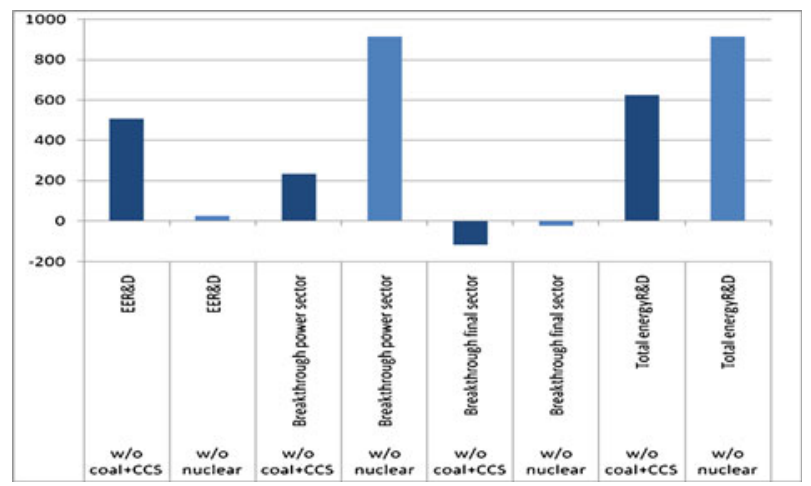

options might fail to fulfil these expectations. ${ }^{5}$ Nuclear fission still faces controversial difficulties with long-term waste disposal and proliferation risks. Coal with CCS can have various drawbacks such as after storage leakage or problems related to transport and storage. Should these options not be in the long-term mitigation portfolio, innovation and diffusion of alternatives technologies would play a much larger role.

Figure 6 shows how investments in innovation would change compared to the case with all options available. Unsurprisingly, most of the adjustment in innovation is shown to occur within the power sector to respond to the constraints on the two electricity generation technologies. When nuclear is constrained to baseline levels, a great deal of additional investments would be dedicated to make competitive the breakthrough technology that can directly substitute traditional nuclear fission. Allocating resources to develop technologies within the power sector (breakthrough power sector) is considered to be more costeffective. The objective of minimising total cost combined with the opportunity cost of each given $R \& D$ program leads to a reduction in energy $R \& D$ investments in the final sector because considered less cost-effective. This option plays an important role also when coal with CCS is not available. However, in this case, the substitution is less direct because CCS and the breakthrough technology appear in different nests of the production tree. In this case, energy efficiency is also more important, together with other zero-carbon alternatives such as wind and solar power. The higher deployment of wind and solar brings about an additional cost reduction due to learning. Most of the effort would be initially borne by developed regions, investing in the technology when costs are still moderately high. This would bring down global costs, inducing a larger use of this technology also in non-OECD countries but with some delay, i.e. starting from 2030. However, this positive effect would not be enough to counteract the technology failure implied by the absence of nuclear or CCS, and policy costs would overall increase (see the companion article in this special issue by Tavoni et al. 2011). This is a general feature in optimisation models, the larger the number of constraints, the higher the costs.

Without major technological breakthroughs, achieving ambitious stabilisation targets would be very expensive because, at the margin, the costs of already exploited options would increase enormously. The possibility of dedicating innovation funds specifically to the development of alternative technologies is thus an important channel of flexibility and not investing sufficient resources in these R\&D programs could increase climate policy costs substantially.

\footnotetext{
${ }^{5}$ In the case of nuclear, which is already deployed in the baseline, this means that no further expansion compared to the baseline is allowed.
} 
Figure 7 shows the consequences on technology deployment of not dedicating investments to advanced $\mathrm{R} \& \mathrm{D}$ programs in the final sector. The technology would be more expensive when initially deployed and also afterward. Higher initial costs delay its use, slowing down the gains from learning and reducing the scope for cost reduction through diffusion. The macroeconomic penalty of not investing in advanced R\&D programs is very large. Discounted consumption losses increase from $1.4 \%$ to $3.3 \%$.

\section{Conclusions and extensions}

This paper analyses how different determinants of climate innovation interact in selected policy scenarios that progressively depart from the assumption of immediate and global participation and of full technology availability. It uses an ex-ante approach based on an integrated assessment model that describes innovation and diffusion of exiting and advanced technologies that can serve as mitigation options, accounting also for international spillovers of knowledge and experience.

Results indicate how differently designed policies can have very diverse effects on the various forms of energy innovation, depending on how various determinants of climate innovation act together. Four major determinants are identified. A first driver is the price of carbon or equivalently the stringency of the climate target. A second driver is the credibility of climate policies and thus the stability of the carbon price they induce. Third, the policy architectures, affecting the distribution of effort across countries, influences the global level of innovation as different countries will contribute differently to the international development and transfer of technologies. The fourth determinant is absorptive capacity which depends among other things on the domestic stock of knowledge.

Results indicate that a stringent policy target imposed on a small group of top innovator countries can lead to more innovation and technology diffusion than what could be obtained by enlarging the group to countries such as China and India. The reason is twofold. On the on hand, most innovative capacity is concentrated in Annex I countries. Second, adding one or two developing countries enlarges the set of cheaper mitigation options available, at the cost of innovation and deployment of the more costly technologies.

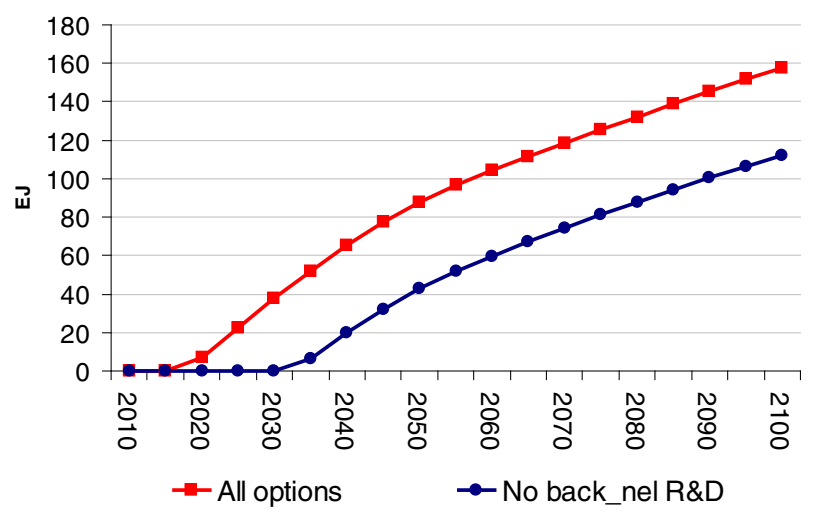

Fig. 7 Deployment of breakthrough technology in final use, non-electric sector without breakthrough innovation 
Expectations about the course of climate policy determine the impact of delayed mitigation policies on innovation and diffusion. Myopic agents that do not foresee the possibility of climate policies in the future under-invest in all forms of innovation and, in particular, in more risky R\&D programs associated with advanced, low-carbon technologies. On the contrary, when the future policy target is credible and countries anticipate it, they immediately start to invest in innovative, breakthrough R\&D programs. The additional innovation effort is mostly concentrated in countries that are at the technological frontier but, because of international spillovers, deployment of the breakthrough technology reaches developing countries as well. In general, postponing mitigation leads to an intertemporal innovation path that is not optimal. Because countries must meet the same climate objective, but within a shorter time frame, they invest more but less efficiently in later periods. This inefficiency creates a macroeconomic penalty that will be larger if agents are myopic.

When countries cannot rely on some mitigation options, such as nuclear power or coal IGCC equipped with CCS, breakthrough innovation in the power sector and deployment of renewables are stimulated. OECD countries start to innovate and increase the use of these technologies first. Because both technological options are characterised by international knowledge and experience spillovers, earlier OECD action brings down global costs, inducing diffusion in non-OECD countries as well, though with a delay.

The possibility of dedicating R\&D funding specifically to the development of alternative technologies is an important channel of flexibility. Not investing resources in these R\&D programs could delay technology deployment and increase climate policy cost substantially. In addition, R\&D investments are order of magnitude smaller than investments in real capital; hence they really represent an option to buy greater flexibility.

Finally, we would like to express a word of caution. Models are a partial representation of reality and rest on important assumptions. In particular, empirical analysis, for example analysing patent data, can only partially help us to estimate crucial parameters of the innovation sector. We test for robustness in our findings to different parameterizations of technical change in the energy sector. We find that the parameters which have by far the largest impact on results are the parameter controlling for the diffusion of and that controlling for the learning-by-doing in breakthrough technologies, suggesting that this is a key empirical area of research to be further explored.

\section{Appendix I. WITCH: A model of endogenous technology and knowledge innovation and diffusion}

The WITCH model describes technological advances that can occur in the energy sector of the economy, distinguishing between invention/innovation and diffusion/deployment. Innovation can either improve energy efficiency or increase competitiveness of advanced, not yet available, zero carbon technologies (breakthrough technologies). In both cases, the process of innovation follows similar dynamics. Knowledge creation is characterised by an innovation possibility frontier that exhibits both intertemporal and international spillovers of knowledge. The flow of new ideas $\left(Z_{J}\right)$ adds to the exiting stock of knowledge $\left(H E_{J}\right)$, depreciated by factor $\delta$, and generates the new stock of knowledge available to each region, indexed by $n$, at each point in time, $t$ :

$$
\begin{aligned}
& H E_{j}(n, t+1)=Z_{j}(n, t)+H E_{j}(n, t)\left(1-\delta_{R \& D}\right) \\
& \mathrm{j}=\text { EE breakthrough, power sector; breakthrough, final sector; }
\end{aligned}
$$


Fig. 8 Innovation possibility frontier normalised with respect to USA

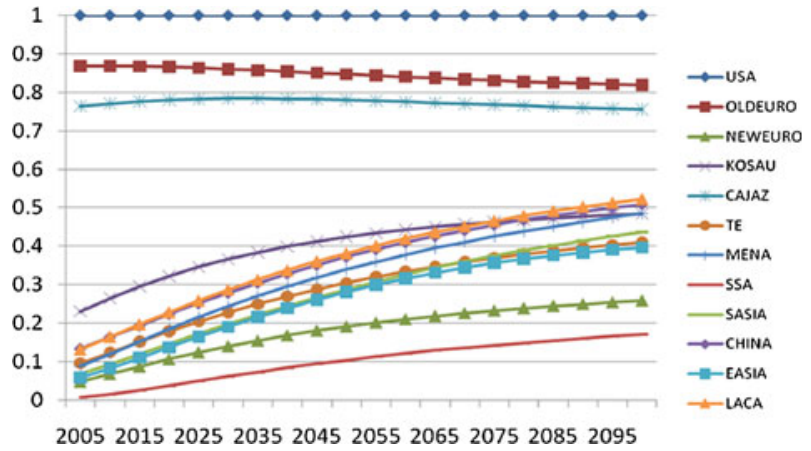

Innovation can have three different applications, indexed by $j$, namely to improve energy efficiency $(E E)$ and to reduce the cost of the two carbon-free technologies (breakthrough, power sector and breakthrough, final sector) and is meant to emphasise that each form of innovation requires specific, dedicated investments, $I_{j}$.

At each point in time, new ideas $\left(Z_{J}\right)$ are produced using a Cobb-Douglas combination between dedicated domestic investments $\left(I_{j, R \& D}\right)$, a domestic stock of knowledge $\left(H E_{J}\right)$ and a foreign stock of knowledge $\left(S P I L L_{J}\right)$ :

$$
\begin{aligned}
& Z_{j}(n, t)=a I_{j, R \& D}(n, t)^{b} H E_{j}(n, t)^{c} \operatorname{SPILL} L_{j}(n, t)^{d} \\
& \mathrm{j}=\mathrm{EE} ; \text { breakthrough, power sector; breakthrough, final sector; }
\end{aligned}
$$

The contribution of foreign knowledge, SPILL $L_{j}$, is not immediate, but depends on the interaction between two components shown in Eq. A3. The first term describes the countries' absorptive capacity whereas the second one captures the distance of each region from the technology frontier. The technology frontier is represented by the sum of the stock of knowledge across high-income countries $H I^{6}$ :

$$
\begin{aligned}
& \operatorname{SPILL}_{j}(n, t)=\frac{H E_{j}(n, t)}{\sum_{n \in H I} H E_{j}(n, t)}\left[\sum_{n \in H I} H E_{j}(n, t)-H E_{j}(n, t)\right] \\
& \mathrm{j}=\mathrm{EE} \text {; breakthrough, power sector; breakthrough, final sector; }
\end{aligned}
$$

Figure 8 depicts the innovation possibility frontier for each country relative to the USA which has been normalised to one. Because rich countries are closer to the frontier, the potential inflow of knowledge is smaller compared to poor countries, despite the higher absorptive capacity (see also Table 1). Over time, developing countries progressively increase their knowledge stock and absorptive capacity but at the same time the potential inflow of knowledge is reduced as they converge to the frontier. Overall, spillovers are relatively higher in developing countries, as it can be seen from Fig. 9, which shows the ratio of international spillovers to the domestic R\&D knowledge stock.

The empirical evidence that could guide the parameter value selection is almost nonexistent (see Bosetti et al. 2008 for a discussion on this issue). They have been chosen so as to assign the largest contribution to the knowledge stock (on average 0.4, close to what assumed in Popp 2004). Domestic R\&D investments contribute to the creation of new ideas with a share of 0.18 whereas international spillovers have a slightly lower contribution of 0.15 (e.g. a $1 \%$ increase in international spillovers increases the output of domestic ideas by $0.15 \%$ ).

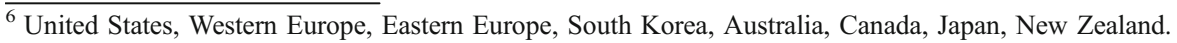




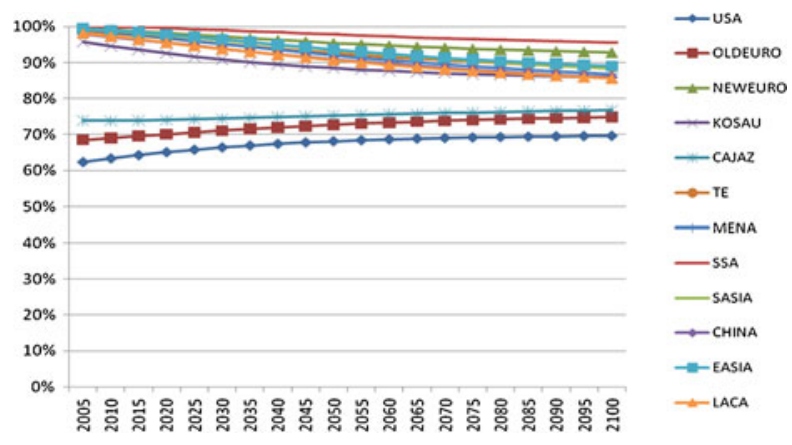

Fig. 9 International spillovers. Ratio to the domestic R\&D knowledge stock

R\&D itself has an opportunity cost. Since we do not model non-energy R\&D, exogenous crowding-out is assumed. Within each given region, domestic externalities are fully internalised and we consider the social return of investment four times larger than the private one. In addition, each dollar spent on energy R\&D crowds out half as much investments in other R\&D (Popp 2004). In Eq. A4 we set $\psi=0.5$ :

$$
\operatorname{COST}_{R \& D}(n, t)=I(n, t)+4 \psi I(n, t)
$$

Each stock of energy knowledge can have an alternative application.

The energy efficiency stock of knowledge augments the quantity of final energy services $(E S)$ that can be provided per unit of physical energy $(E N)$ according to a Constant Elasticity formulation:

$$
E S(n, t)=\left(\alpha_{H} H E_{e n}(n, t)^{\rho_{E N}}+\alpha_{e n} E N(n, t)^{\rho_{e n}}\right)^{\frac{1}{\rho e n}}
$$

This is a formulation that can be used to describe energy efficiency improvements (see also Popp 2004) because an increase in the stock of knowledge substitutes for the physical input of energy, reducing emissions per unit of energy services provided.

The stock of energy knowledge can also reduce the unit cost of breakthrough technologies. The cost of each technology is described by a two-factor learning curve which also considers the role of diffusion (Kouvaritakis et al. 2000). The unit cost of technology, $P_{t e c}(n, t)$, at time $t$ is a function of global deployment, $\sum K_{\text {tec }}(n, t)$, which accrues with technology investments or deployment in the case of ${ }^{n}$ the final sector breakthrough and a dedicated energy knowledge stock, $H E_{t e c}(n, t)$. To roughly capture the lag exiting between research and commercialisation, innovation has an impact on costs with a delay of two periods which in the model correspond to 10 years:

$$
\frac{P_{t e c}(n, t)}{P_{t e c}(n, 0)}=\left(\frac{H E_{t e c}(n, t-2)}{H E_{t e c}(n, 0)}\right)^{-c} *\left(\frac{\sum_{n} K_{t e c}(n, t)}{\sum_{n} K_{t e c}(n, 0)}\right)^{-b}
$$

tec $=$ breakthrough, power sector; breakthrough, final sector;

The R\&D stock accumulates with the perpetual rule and with the contribution of international knowledge spillovers, as in Eq. A1. The R\&D expenditure devoted to breakthrough technologies prior 2005 has been very small. As a consequence, we omit the contribution of the knowledge stock which however is negligible. To give a term of comparison, the total stock of energy knowledge computed using International Energy 
Agency statistics amounts at 120 2005US\$ billion in 2005. Only 4 billion can be attributed to a technology that could represent a breakthrough, namely concentrated solar power.

The two exponents are the Learning-by-Doing index $(-b)$ and the Learning-byResearching index $(-c)$. They define the speed of learning due to diffusion and deployment (Learning-by-Doing) and to innovation (Learning-by-Researching). They are derived from a learning ratio which is the rate at which the generating cost declines each time the cumulative capacity or the knowledge stock doubles.

This formulation has received significant attention from the empirical and modelling literature in the most recent past (Criqui et al. 2000; Barreto and Kypreos 2004; Klassen et al. 2005; Kypreos 2007; Jamasab 2007; Söderholm and Klassens 2007). Table 2 summarises some estimates of parameters controlling the learning processes mostly for technologies used in the power sector and it shows a large variability. Based on those estimates, we assumed values in the lower range which are reported in the last row of the table. Note that the value chosen for the Learning-by-Doing parameter is lower than those normally estimated in single factor experience curves since part of the technology advancement is now led by specific investments.

Finally, it must be highlighted that modelling of long-term and uncertain phenomena such as technological evolution calls for caution in the interpretation of exact quantitative figures and for accurate sensitivity analysis. The model parsimony allows for tractable sensitivity studies as stressed above. One should nonetheless keep in mind that the economic implications of climate policies as well as carbon price signals are influenced by innovative technologies availability only after 2030 .

Once competitive, the uptake of the two breakthrough technologies is not immediate and complete but there is a transition/adjustment period. These penetration limits reflect the inertia of current energy and transport systems. The upper limit on penetration is set equal to $5 \%$ of electricity generation from other technologies in the case of the electric backstop and to $5 \%$ of consumption of other energy carriers in the case of non-electric backstop.

Initial prices are about ten times the 2005 price of commercial equivalents (16,000 US\$/ $\mathrm{kW}$ for electric, and $550 \mathrm{US} \$ / \mathrm{bbl}$ for non-electric). The cumulative deployment is initiated at 1,000 TWH and 1,000 EJ, for the electric and non-electric backstop, respectively, an arbitrarily low value (Kypreos 2007). The backstop technologies are assumed to be renewable in the sense that the fuel cost component is negligible; for power generation, it is assumed to operate at load factors comparable with those of base load power generation.

Table 2 Learning ratios for diffusion (LbD) and innovation (LbR) processes

\begin{tabular}{llll}
\hline Technology & Author & LbD & LbR \\
\hline Wind & Criqui et al. 2000 & $16 \%$ & $7 \%$ \\
& Jamasab 2007 & $13 \%$ & $13.2 \%$ \\
& Söderholm and Klassen 2007 & $12.6 \%$ \\
PV & Klassen et al. 2005 & $3.1 \%$ & $10 \%$ \\
Solar Thermal & Criqui et al. 2000 & $20 \%$ & $5.3 \%$ \\
Nuclear Power (LWR) & Jamasab 2007 & $2.2 \%$ & $24 \%$ \\
CCGT (1980-89) & Jamasab 2007 & $37 \%$ & $18 \%$ \\
CCGT (1990-98) & Jamasab 2007 & $0.7 \%$ & $2.4 \%$ \\
WITCH & Jamasab 2007 & $2.2 \%$ & $13 \%$ \\
\hline
\end{tabular}


Once competitive, deployment and technology diffusion contribute to further reduce the costs of backstop technologies. This is the second component of Eq. A5. International spillovers characterise also the diffusion phase and thus technology costs depend on the capacity installed globally. Differently from knowledge spillovers occurring during the innovation phase, experience spillovers that are embodied in the use of the technology are free and immediate within the period time step of the model which is 5 years.

Learning-by-doing also affects the cost of wind and solar photovoltaic power. In this case, most cost reduction comes from increased deployment and the cost, $S C(n, t+1)$, follows a one-factor learning curve and declines with the world installed capacity, $\sum_{n} K(n, t)$ :

$$
S C(n, t+1)=B(n) \cdot \sum_{n} K(n, t)^{-\log _{2} P R}
$$

The progress ratio, $P R$, defines the speed of learning. Although the econometric approach used to estimate learning curves and ratios has recently been criticised by Nordhaus (2009), there is evidence for a negative relationship between capacity and costs. For example, the annual world market for wind turbines has increased to tens of billions of dollars over the last two decades and the price of turbines has been reduced by a factor of four (Nemet 2010).

Without any policy, investment costs decline from the initial level 1,906US $\$ \mathrm{~kW}$ in 2005 to 1,010 in 2050 and 649 in 2100 with an overall reduction of about $66 \%$. With a stabilisation policy (550 ppm $\mathrm{CO}_{2}$-eq), investment costs can be lowered to reach the floor price of US\$ 500 .

\section{References}

Baker E, Shittu E (2006) Profit maximizing R\&D investment in response to a random carbon tax. Resource Energ Econ 28:105-192

Barreto L, Kypreos S (2004) Endogenizing R\&D and market experience in the bottom-up energy-systems ERIS model. Technovation 2:615-629

Bastianin A, Favero A, Massetti E (2010) Investments and financial flows induced by climate mitigation policies. FEEM Working Paper No. 13, Fondazione Eni Enrico Mattei, Milan.

Binswanger HP, Ruttan VW (1978) Induced innovation: technology institutions and development. John Hopkins University Press, Baltimore

Blanford GJ (2009) R\&D Investment strategy for climate change. Energy Econ 31(S1):S27-S36

Bosetti V, Victor DG (2010) Politics and Economics of Second-Best Regulation of Greenhouse Gases: The Importance of Regulatory Credibility, FEEM Working Paper No. 29, Fondazione Eni Enrico Mattei, Milan.

Bosetti V, Carraro C, Galeotti M, Massetti E, Tavoni M (2006) WITCH: a world induced technical change hybrid model. The Energ J, Special Issue on Hybrid Modeling of Energy-Environment Policies: Reconciling Bottom-up and Top-down, 13-38

Bosetti V, Carraro C, Massetti E, Tavoni M (2008) International energy R\&D spillovers and the economics of greenhouse gas atmospheric stabilization. Energ Econ 30:2912-2929

Bosetti V, Carraro C, Tavoni M (2009a) Climate change mitigation strategies in fast-growing countries: the benefits of early action, CESifo Working Paper No. 2742.

Bosetti V, Carraro C, Duval R, Sgobbi A, Tavoni M (2009b) The role of R\&D and technology diffusion in climate change mitigation: new perspectives using the WITCH model. OECD Working Paper No. 664, February.

Bosetti V, Carraro C, Duval R, Tavoni M (2010) What should we expect from innovation? A model-based assessment of the environmental and mitigation cost implications of climate-related R\&D, FEEM Working Paper No. 42, Fondazione Eni, Milan.

Bürer MJ, Wüsternhagen R (2009) Which renewable energy policy is a venture capitalist's best friend? Empirical evidence from a survey of international cleantech investors. Energ Pol 37:4997-5006 
Carraro C, De Cian E, Tavoni M (2009a) Human capital formation and global warming mitigation: evidence from an integrated assessment model, CESifo Working Paper No. 2874.

Carraro C, Massetti E, Nicita L (2009b) How does climate policy affect technical change? An analysis of the direction and pace of technical progress in a climate-economy model. The Energ J 30(2):7-38

Carraro C, De Cian E, Massetti E, Nicita L, Verdolini E (2010) Environmental policy and technical change: a survey. Int Rev Environ Resour Econ 4:163-219

Coe DT, Helpman E (1995) International R\&D spillovers. Eur Econ Rev 39(5):859-887

Criqui P, Klassen G, Schrattenholzer L (2000) The efficiency of energy R\&D expenditures. Economic modeling of environmental policy and endogenous technical change, Amsterdam, November 16-17, 2000

De Cian E, Tavoni M (2010) The role of international carbon offsets in a second-best climate policy: a numerical evaluation. FEEM Working Paper, No. 33, Fondazione Eni Enrico Mattei, Milan.

Dechezleprêtre A, Glachant M, Ménière Y (2008) The clean development mechanism and the international diffusion of technologies: an empirical study. Energ Pol 36:1273-1283

Dechezleprêtre A, Glachant M, Johnstone N, Haščič I, Ménière Y (2009) Invention and transfer of climate change mitigation technologies on a global scale: a study drawing on patent data, FEEM Working Paper 082.2009.

Gerlagh R (2008) A climate-change policy induced shift from innovations in carbon-energy production to carbon-energy savings. Energ Econ 30(2):425-448

Gerschenkron A (1962) Economic backwardness in historical perspective. Harvard University Press.

Gillingham K, Newell RG, Pizer WA (2008) Modelling endogenous technological change for climate policy analysis. Energ Econ 30:2734-2753

Goulder L, Schneider S (1999) Induced technological change and the attractiveness of $\mathrm{CO}_{2}$ emissions abatement policies. Resource Energ Econ 21:211-253

Grossman G, Helpman E (1991) Innovation and growth in the global economy. The MIT Press, Cambridge

Hart R (2008) The timing of taxes on $\mathrm{CO}_{2}$ emissions when technological change is endogenous. J Environ Econ Manage 55(2):194-212

Hicks JR (1932) The theory of wages. McMillan, London

Jamasab T (2007) Technical change theory and learning curves: patterns of progress in electric generation technologies. The Energ J 28(3)

Keller W (2004) International technology diffusion. J Econ Lit 42(3):752-782

Kennedy C (1964) Induced bias in innovation and the theory of distribution. Econ J 74(295):541-547

Klassen G, Miketa A, Larsen K, Sundqvist T (2005) The impact of R\&D on innovation for wind energy in Denmark, Germany and the United Kingdom. Ecol Econ 54(2-3):227-240

Kouvaritakis N, Soria A, Isoard S (2000) Endogenous learning in world post-Kyoto scenarios: application of the POLES model under adaptive expectations. Int J Global Energ Issues 14(1-4):228-248

Kypreos S (2007) A MERGE model with endogenous technical change and the cost of carbon stabilisation. Energ Pol 35:5327-5336

Löschel A (2002) Technological change in economic models of environmental policy: a survey. Ecol Econ 43(2-3):105-126

Luderer G, Bosetti V, Jakob M, Leimbach M, Steckel JC, Waisman H, Edenhofer O (2011) The economics of decarbonizing the energy system-results and insights from the RECIPE model intercomparison. Climatic Change. doi:10.1007/s10584-011-0105-x.

Meyer A (2004) Briefing: contraction and convergence. Eng Sustain 157(4):189-192

Nemet GF (2010) Robust Incentives and the Design of a Climate Change Governance Regime, La Follette School Working Paper No. 2010-006.

Nordhaus WD (2009) The Perils of the learning model for modeling endogenous technological change, NBER Working Paper 14638.

Otto VM, Löschel A, Reilly J (2008) Directed technical change and differentiation of climate policy. Energ Econ 30(6):2855-2878

Peri G (2005) Determinants of knowledge flows and their effects on innovation. The Rev Econ Stat 87 (2):308-322

Popp D (2002) Induced innovation and energy prices. Am Econ Rev 92(1):160-180

Popp D (2004) ENTICE: endogenous technological change in the DICE model of global warming. J Environ Econ Manage 48(1):742-768

Popp D (2006) International innovation and diffusion of air pollution control technologies: the effects of NOX and SO2 regulation in the U.S., Japan, and Germany. J Environ Econ Manage 51(1):46-71

Popp D, Hafner T, Johnstone N (2007) Policy vs. consumer pressure: innovation and diffusion of alternative bleaching technologies in the pulp industry. NBER Working Paper 13439 
Popp D, Newell R, Jaffe A (2009) Energy, the Environment, and Technological Change NBER Working Paper Series, No 14832, April 2009.

Rosenberg N (1982) Inside the black box: technology and economics. Cambridge University Press, Cambridge

Rosenberg N (1994) Exploring the black box: technology, economics, and history. Cambridge University Press, Cambridge

Schmookler J (1966) Invention and economic growth. Harvard University Press, Cambridge

Seres S, Haites E, Murphy K (2009) Analysis of technology transfer in CDM projects: an update. Energ Pol 37:4919-4926

Söderholm P, Klassen G (2007) Wind power in Europe: a simultaneous innovation-diffusion model. Environ Res Econ 36(2):163-190

Sue Wing I (2003) Induced technical change and the cost of climate policy. MIT Joint Program on the Science and Policy of Global Change, Report No. 102, September 2003.

Tavoni M, De Cian E, Luderer G, Steckel J (2011) The value of technology and of its evolution towards a low carbon economy. Climatic Change, forthcoming

Verdolini E, Galeotti M (2009) At home and abroad: an empirical analysis of innovation and diffusion in energy-efficient technologies, FEEM Working Paper 123.2009. 